\title{
Traditional Medicine: Safety Evaluation-Need of the Hour
}

\section{Narasimha GVK*, Dayanand RG and Pullaiah CP \\ Department of Pharmacology, Siddha Central Research Institute, India}

*Corresponding author: GV Narasimha Kumar, Department of Pharmacology, Siddha Central Research Institute, Anna Government Hospital Campus,

\section{Mini Review}

Volume 2 Issue 7

Received Date: September 07, 2018

Published Date: September 28, 2018

DOI: $10.23880 /$ jonam- 16000152

Arumbakkam, Chennai-600106, Tamilnadu, India, Tel: +91-9949102404; Email: narasimha.spsp@gmail.com

\section{Abstract}

Traditional systems of medicines played a key role in global healthcare system especially in rural areas. Indian traditional medicinal system is one of the oldest traditional medicinal systems in the world. India has six distinctive traditional systems of medicine; they are Ayurveda, Siddha, Unani, Yoga, naturopathy, and homeopathy. In Asian and African countries, up to $80 \%$ of the population relies on traditional medicine for their primary health care needs. Even though these alternative systems of medicines have wide range of therapeutic uses, improper usage of these medicines leads to serious superfluous effects. Hence, there is a strong need for carrying out safety evaluation of traditional medicines with globally accepted guidelines.

Keywords: Traditional Medicine; Safety; WHO; Herbs

\section{Introduction}

Health is an elementary human value. Consequently, most cultures have sought after and used a broad range of healing practices [1]. For thousands of years, traditional medicine (TM) has been an important source of health care of the world, and many populations use and value TM not only as the source of their primary health care but also part of their cultural and spiritual belief systems. The World Health Organization defines TM as-"Diverse health practices, approaches, knowledge and beliefs incorporating plant, animal, and/or mineral based medicines, spiritual therapies, manual techniques and exercises applied singularly or in combination to maintain well being, as well as to treat, diagnose or prevent illness" [2].

The last two decades have witnessed globally renewed interest in the use of traditional, complementary and alternative medicine [3]. The use of traditional medicine is even more substantial in the developing world. According to data provided to WHO, in India 70 percent of the population and in Ethiopia more than 90 percent of the population depend on TM for primary health care [4]. It is reported that more than 70 percent of the population in Chile and 40 percent of the population in Colombia have been using traditional medicine [5].

Traditional medicine is not only a vital source of health care, but also an important source of income for many communities. This economic activity supports many indigenous peoples and local communities, a benefit that in turn provides incentives for the conservation of TM [6]. Thus there is a chance of economic exploitation of traditional medicine as it is believed that they are completely safe because they are "natural" and have a long history of usage. 


\section{Journal of Natural \& Ayurvedic Medicine}

But on the other side, the use of traditional medicine presents unique public health challenges. WHO notes that "inappropriate use of traditional medicines or practices can have negative or dangerous effects" and that "further research is needed to ascertain the efficacy and safety" of many traditional medical practices [7]. For example, the use of TM may delay the effective allopathic treatment, which can cause direct adverse effects. Health risks may be posed by drug-herb interactions and problems related to quality control [8]. Thus TM needs rigorous, scientific data to demonstrate its efficacy and it also needs evidence-based standards for quality and safety evaluation to support its appropriate regulation.

\section{Current Scenario}

Traditional medicines may be regulated with appropriate prescription or as over-the-counter medicines or dietary supplements and should have effective marketing strategies with medical, health or nutritional claims respectively. Modern regulations on traditional medicine in India has been included in Drugs and Cosmetics Act 1940, which contained a separate chapter and rules (Drugs and Cosmetics Act Rules 1945) for Ayurveda, Siddha and Unani drugs [9]. The Act amended in the year 2000, requires government license for manufacturing and sales of traditional medicines. The central government is empowered to inspect and analyze traditional medicines. Manufacturers of traditional medicines required to adhere to good manufacturing practices, as well as requirements related to factory premises and heavy metal contents. Heavy metals are sometimes considered active ingredients of Indian Traditional medicines rather than contaminants, but heavy metal testing is mandatory now a days. In addition, heavy metals may not be present to the above permissible limits, and should be labeled its quantity [10].

Traditional medicine manufacturers are also required to adhere to the information contained in national pharmacopoeias and monographs. Safety requirements for traditional medicines are less when compared to those applied to pharmaceuticals, and generally there is no submission requirement for clinical trials demonstrating safety and efficacy [11]. The ministry of Ayurveda, Yoga and Naturopathy, Unani, Siddha and Homeopathy (AYUSH) is primarily responsible for the regulation of traditional medicines in India. In the year 1989, WHO also urged member states to make a comprehensive evaluation of their traditional systems of medicine, to make a systematic inventory and assessment (preclinical and clinical) of the medicinal plants used by traditional practitioners and by the population, to introduce measures for the regulation and control of medicinal plant products for the establishment and maintenance of suitable standards. To identify those medicinal plants, or remedies derived from them, which have a satisfactory efficacy/side-effect ratio and which should be included in national formularies or pharmacopoeias [7].

Good manufacturing practices (GMPs) help to ensure that the products are consistently manufactured with appropriate quality standards. WHO Good manufacturing practices guidelines are used by pharmaceutical manufacturers and regulators in over 100 countries worldwide, primarily in the developing world. The European Medicine Agency (EMA) and the U.S. Food and Drug Administration (USFDA) GMP requirements are needed in certain cases to apply more rigorous standards. Many countries do not require manufacturers of traditional medicines to adhere to GMP guidelines. Which results in the manufacturers may be responsible for making a quality and safety medicine ${ }^{11}$. Enforcing GMPs may help address the issue of contaminated or adulterated supplements. GMPs provide requirements for the manufacturing of herbs that encompass quality control of materials, accurate identification of medicinal plants species, and procedures for harvesting and storing herbs [7]. WHO has long advocated that ensuring GMPs is a critical part of effective national policies on traditional medicine.

\section{Conclusion}

The development of the pharmaceutical industry and the unceasing growth of new and more effective synthetic and biological medicinal products have not diminished the importance of traditional medicine in the world. On the contrary, population growth in the developing world and increasing interest in the industrialized nations have greatly expanded the demand for traditional medicine and preparations, methods involved in it. Regulations in countries for the assessment of the quality, safety and efficacy of traditional medicine, and the work of WHO in supporting the preparation of model guidelines in this field, have been helpful in strengthening recognition of their role in health care. It is hoped that assessment of these traditional remedies could become the basis for a future classification of these medicines, as well as for evaluative studies on their efficacy and safety, and their potential use in national health care systems in different parts of the world. 


\section{Journal of Natural \& Ayurvedic Medicine}

\section{References}

1. Brigg JP (2014) The Art and Science of Traditional Medicine Part 1: TCM Today-A Case for Integration Science 346(6216): 1569.

2. WHO (2003) Traditional Medicine pp: 1-4.

3. Barnes PM Bloom B, Nahin RL (2008) Complementary and Alternative Medicine Use Among Children: United States, 2007. Natl Health Stat Report 10(12): 1-23.

4. WHO (2013) TM Strategy, supra note 4, at 9.

5. WHO (2014) TM Strategy, supra note 4, at 11.

6. Srivastava K, Lambert J, Vietmeyer N (1996) World Bank Technical Paper, Medicinal Plants: An Expanding Role in Development. pp: 1-36.

7. WHO (2007) WHO Guidelines for assessing quality of herbal medicines with reference to contaminants and residues. pp: 1-118.
8. Abbott R (2014) Documenting Traditional Medical Knowledge, World Intellectual Property Organization, pp: 1-52.

9. (2016) Ministry of Health and Family Welfare, Central Drug Standards Control Organization, Laws Pertaining to Manufacture and Sale of Drugs in India. pp: 1-635.

10. Mukherjee PK (2007) An Overview on the Development in Regulation and Control of Medicinal and Aromatic Plants in the Indian System of Medicine, Boletín Latinoamericano y del Caribe de Plantas Medicinales y Aromáticas 6(4): 129-136.

11. WHO (2005) National Policy on Traditional Medicine and Regulation of Herbal Medicines-Report of a WHO Global Survey. pp: 121-122.

12. Institute of Medicine of the National Academies [IOM] (2005) Complementary and Alternative Medicine in the United States. pp: 258-260.

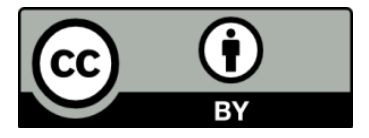

